\title{
A Design on the Communication Protocol for Data Collection of the IOT Based on Cold Chain System
}

\author{
Dae-Sik Ko \\ Mokwon University, Korea \\ $k d s @ m o k w o n . a c . k r$
}

\begin{abstract}
This paper designed and analyzed the communication protocol for the data communication between the IOT device and the middleware server of the IOT based Cold Chain Monitoring System. In this regard, we have referenced the CoAP Protocol Model of IETF CORE WG, and analyzed and designed the process status flow, data flow and frame format of the IOT device (IOTD) and the middleware server. In order to test the effectiveness of the proposed Cold Chain Communication Protocol, we have produced the Zigbee, Bluetooth and wifi module mounted gateway and the temperature, humidity sensor. After sending the temperature data from the IOTD to the middleware server, we analyzed the received data from the middleware server. As the resul, we were able to interpretate the data sent from the IOTD, and identify that in using these data the cold chain data such as the temperature, humidity and battery remains data can be collected in real time.
\end{abstract}

Keywords: cold chain, protocol design, templerature management, IOT, data frame design

\section{Introduction}

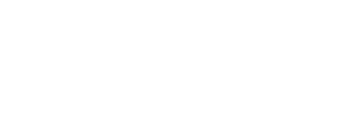

With the recent development of the signal processing technology, miniaturization of various sensors, and increase of needs for consumer-driven data services, IOT services that can be monitored anytime anywhere are expanding. However, even with the communication vith various sensors, there are many difficulties in data sharing due to the unstandardized sensor data and communication protocol [1-2].

The cold chain monitoringsystem refers to a system that controls the state of control by collecting the real time data of agriculture and fishery products and medicines [1-2] In order to provide LTCold chain framework based services, continuous communication between the control server and IOT device is necessary. In servers and clients that use the cold chain framework, in other words, the communication protocol model between the middleware server and the IOT sensor device, reliability is also important due to the characteristics of sensor signals in IOT environments, but it has the characteristic of requiring the collection of continuously changing measurements from numerous sensor nodes. Therefore, this paper has referenced the CoAP protocol model of IETF CoRE WG, which is low in protocol processing load, and excellent in the compatibility of accommodating various sensors [3].

The CoAP protocol model of IETF CoRE WG needs to satisfy several requirements for the interoperability guarantee. In the CoAP protocol, we attempted to secure the simplicity of the protocol by dividing the message transmission processes of messages that require and do not require reliability in the message transmitting and receiving process. In cases that require reliability, data is sent from the Client to the Server, and a confirmation process on the data reception was placed in the server. In cases that do not require reliability, data is sent by the client from the server, and do not require the server to perform a confirmation process on the data reception [3-4]. 
This paper designed and analyzed the communication protocol for the data communication between the IOT device and the middleware server of the IOT based Cold Chain Monitoring System. In this regard, we have referenced the CoAP Protocol Model of IETF CoRE WG, and analyzed and designed the process status flow, data flow and frame format of the IOTD and the middleware server.

Lastly, In order to test the effectiveness of the proposed Cold Chain Communication Protocol, we have produced the gateway and the temperature, humidity sensor. After sending the temperature data from the IOTD to the middleware server, we analyzed the received data from the middleware server.

\section{Design of the IOT Based Cold Chain Communication Protocol}

\subsection{Communication Protocol between the IOTD and the Middleware Server}

A. Connection Type Design

The communication connection type between the cold chain IOTD and the middleware server can be divided into a 1-step connection type ( 2 Tier Type) where the IOTD is directly connected to the middleware server, and a 2-step cohnection type (3.Ther Type) where a router, gateway, or a coordinator acts as a intermediate between the JOTD and the middleware server. As such, even when the connection ypes are categorized differently, a communication model should only define the interface standard between the IOTD and the middleware server. Also, a router, gateway, or a coordinating device should deliver data transparently without playing any role between the IOTD and the middleware server, and indicate the distinct ID of the specific device, [5-7].

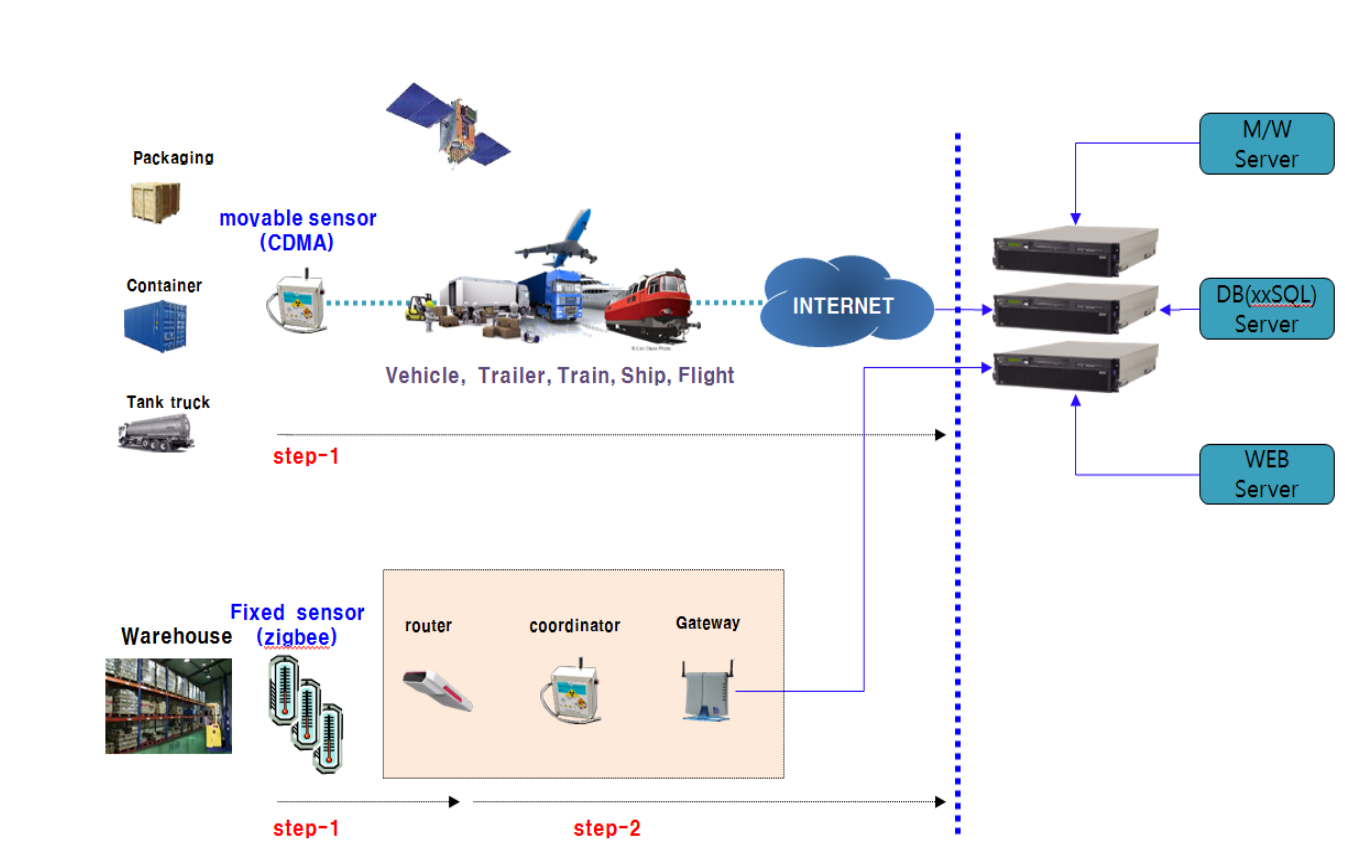

Figure 1. Connection types for Communication between IOTD and Middleware Server (Upper: 2-Tier Type), (Lower: 3-Tier Type)

\section{B. IOTC and Process Status Flow of Middleware Server}

The communication between the IOTD and the middleware server operates as a client/server model. At this time the middleware server acts a server, the IOTD as a client, and as one part of the IOTD, a gateway in a connection model is simply regarded as a part of the IOTD. IOTD and the middleware server uses the TCP Socket Communication of TCP/IP for communication. On the protocol process, middleware server multiplexes the 
process to process the data sent by multiple IOTDs without loss, and these processes performs their function using the inter process communication. Although IOTD uses a simple TCP/IP protocol, it has a n:1 communication structure with the communication model(CM) of MWS because of the large number of sensor types and numbers [8-9].

C. IOTD and MWS Communication Protocol Design

The sensor data flow between the IOT device (IOTD) and the middleware server (MWS) is as represented in Figure 2.

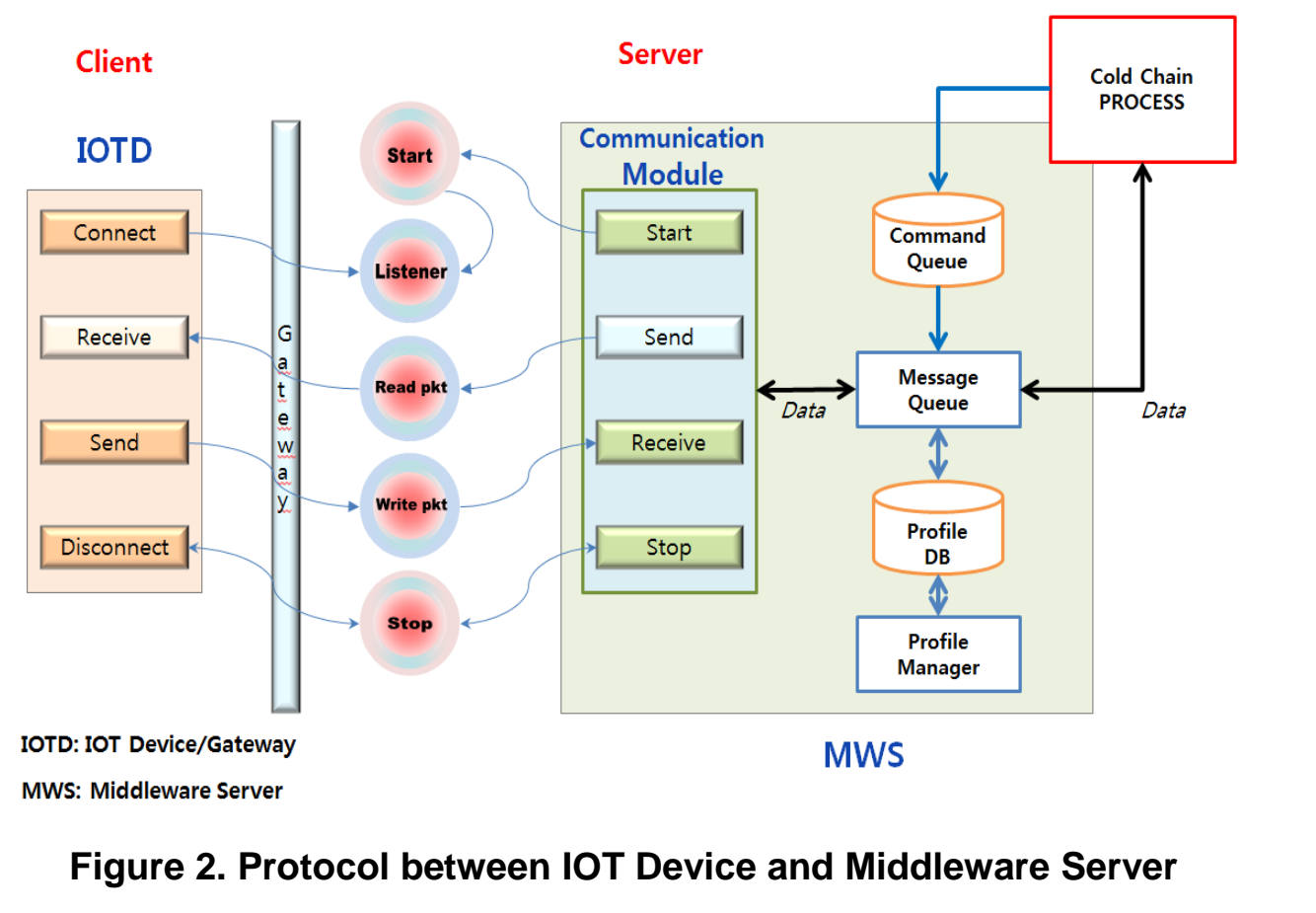

Figure 2 is the IOTD and middleware server process status in the Client/Server format. Communication protocol uses the TCP Socket which is much used in most IOT communication methods. Communication protocol assigns some of the unknown ports. The basic protocor, applied by des gning from the cold chain framework, is expressed as Figure 3 following the ASN.1 format. Applying the standard CoAP protocol, it was designed to enable reliability and unreliability message transmissions also in the protocol model of the cold chain framework [3-4].

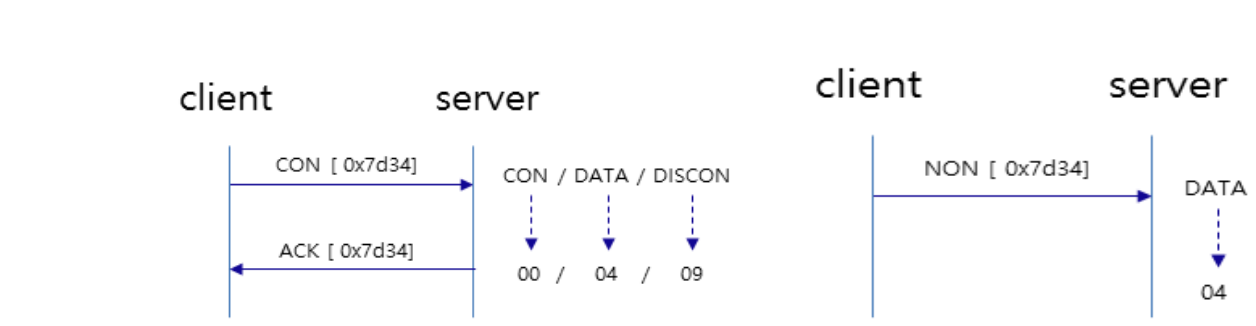

a. Reliability Message Transmission b. Unreliability Message Transmission

Figure 3. Basic Protocol Format of Cold Chain Framework 


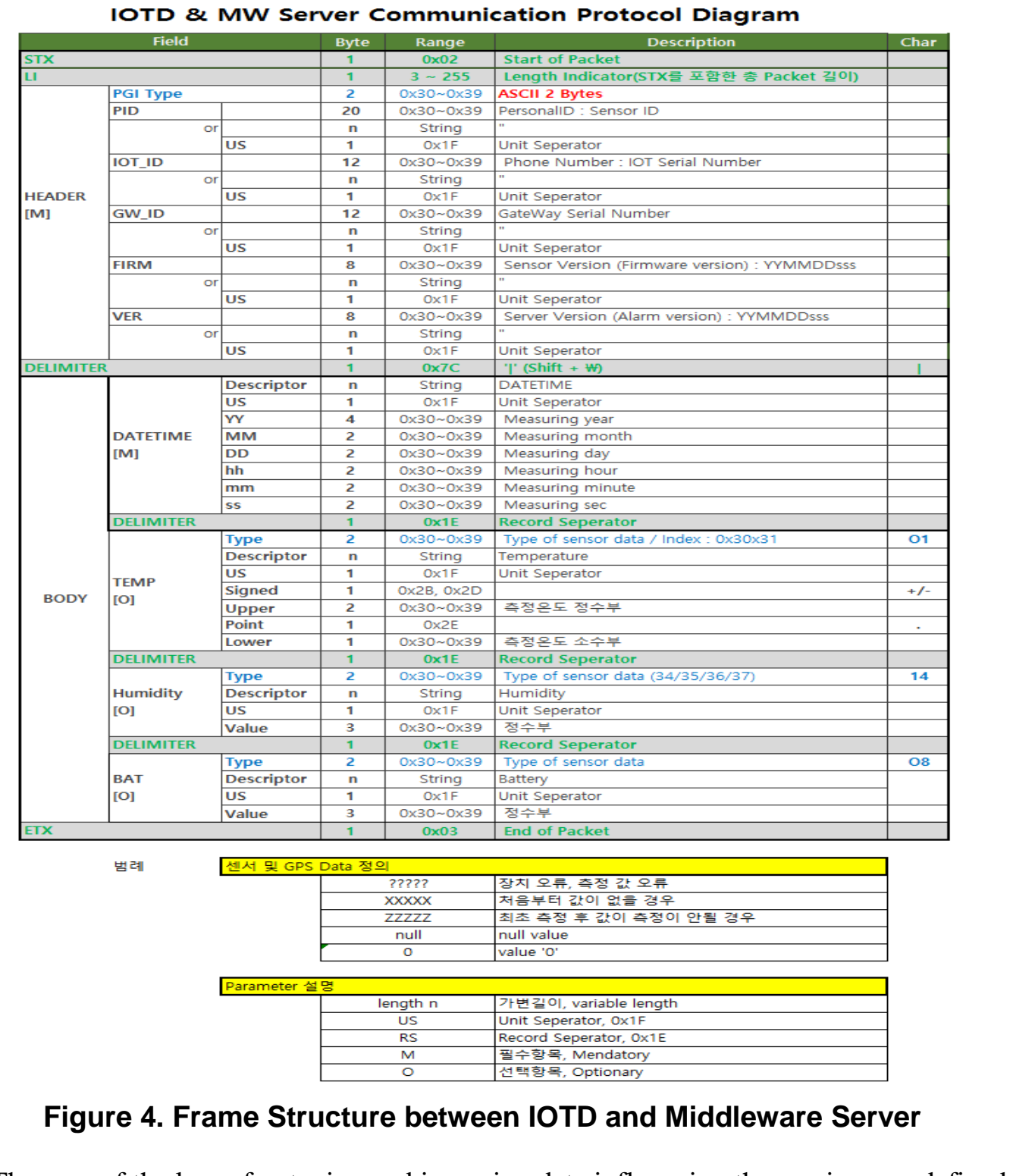

The case of the loss of outgoing and incoming data influencing the service was defined as in Figure 4, to transmit and receive CON/ACK signals between the client and server at all times, and through this secured reliability. In cases of relatively low data reliability, it was designed to only transmit sensor data between the client and server as in $\mathrm{b}$ of Figure 3 and enabled high speed processing through this. But since it is fundamentally based on the reliability of TCP/IP, it is judged to have rarely any data loss.

D Server (MWS)/Client(IOTD) Protocol Packet Structure of cold chain framework

Theoverall data frame structure between the IOTD and MWS is as shown in Figure 4.

Since in Figure 4, each primitive uses fixed and variable intermixedly on the protocol frame structure, the overall frame length cannot be fixed and the DateTime primitive of the header and body is always transmitted basically. The minimal length of the proposed cold chain protocol frame is 90 bytes, not exceeding the maximum length of 512 bytes, and it does not perform any separate data error tests.

PGI of Figure 4, as the Primary Group Index categorizing by protocol type, has the same results as Table 1, and has expandability for the addition of sensor connection network types. 
Table 1. PGI Definition

\begin{tabular}{|c|c|c|c|}
\hline PGI Name & Set number & Description & Note \\
\hline BT Classic & "10“ & BT Classic & '0x310x30‘ \\
\hline BLe & "11" & BLe & ${ }^{\prime} 0 \times 310 \times 31^{\prime}$ \\
\hline WiFi & "12" & WiFi & ${ }^{\prime} 0 \times 310 \times 32^{\prime}$ \\
\hline ZIGBEE & "13“ & ZIGBEE & '0x310x33' \\
\hline UWB & "14" & UWB & ${ }^{\circ} 0 \times 310 \times 34^{\circ}$ \\
\hline IrDA & "15" & IrDA & ${ }^{\circ} 0 \times 310 \times 35^{\circ}$ \\
\hline NFC & "16" & NFC & ${ }^{\circ} 0 \times 310 \times 36^{\circ}$ \\
\hline RFiD & "17"“ & RFiD & ${ }^{\circ} 0 \times 310 \times 37^{\circ}$ \\
\hline CDMA(LTEx) & "18“ & CDMA(LTEx) & ${ }^{\circ} 0 \times 310 \times 38^{\circ}$ \\
\hline LPWA & "19“" & LPWA & '0x310x39" \\
\hline WiBro & “20“ & WiBro & \\
\hline WiMax & "21" & WiMax & $0 \times 320 \times 31^{\circ}$ \\
\hline \multirow[t]{2}{*}{ Skinplex } & " 22 " & Skinplex & $0 \times 320 \times 32^{\circ}$ \\
\hline & & & served for Future "29" \\
\hline RS232C & “30" & & $0 \times 330 \times 30^{\circ}$ \\
\hline RS422 & "31" & & '0x330x31‘ \\
\hline RS485 & "32" & & $0 \times 330 \times 32 ‘$ \\
\hline USB & “33“ & USBS & ${ }^{\prime} 0 \times 330 \times 33^{\prime}$ \\
\hline FIREWIRE & "34" & FIREWIRE & '0x330x34' \\
\hline PLC & & & '0x33 0x35' \\
\hline & & & // Reserved for Future "39" \\
\hline
\end{tabular}

\section{Experimentál Results}

In order to test the effectiveness of the proposed protocol, this paper has collected temperature data in real time by implementing the sensor, gateway hardware, and software. Figure 5 is a block diagram of the test system.

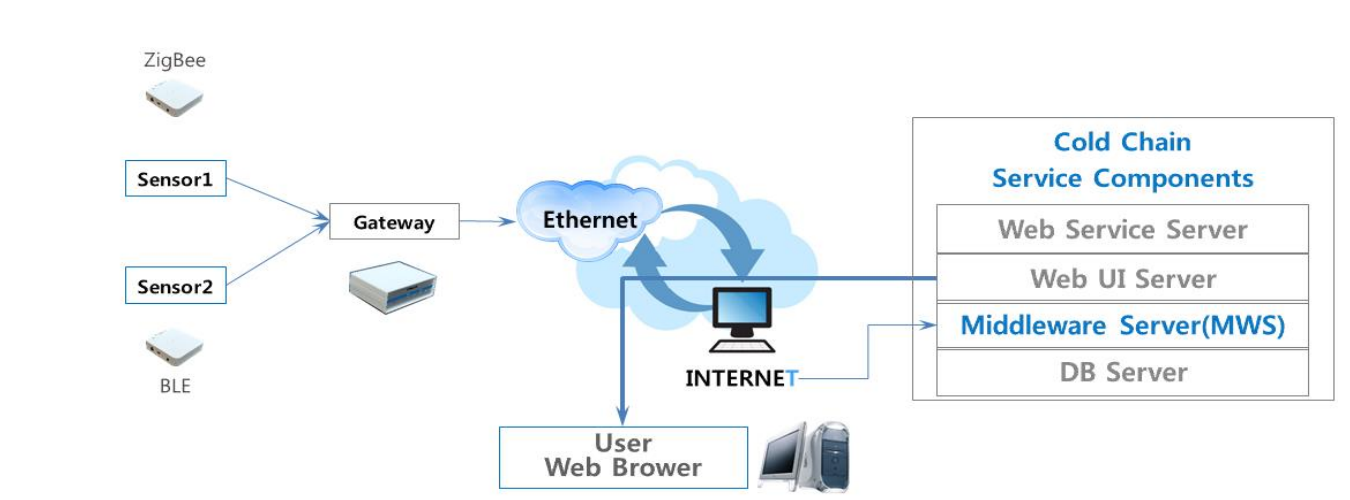

Figure 5. Block Diagram of Test System 
To perform tests, Sensor1 used ZigBee and Sensor2 was produced to communicate in the Beacon mode of Ble. Gateway accessed the internet(Public IP Network) through a hub that uses a private IP, and cold chain components were constituted using public IP. MS Windows 2012 for server, MS-SQL 2014 for DB, and MS Visual Studio 2015 for developing tools were used. Figure 6 is the received data from the BLE Sensor IOTD and Table 2 is its interpretation.

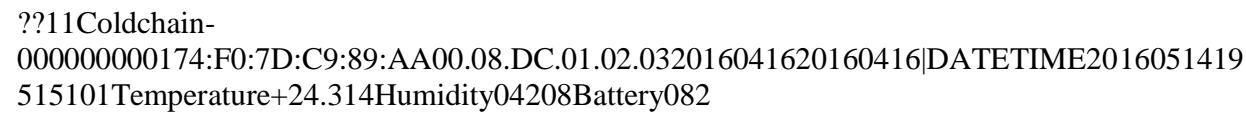

0298313143 6F 6C 6463686169 6E 2D 30303030303030303031 1F 3734 3A 4630 3A 3744 3A 43 39 3A 38 39 3A 4141 1F 3030 2E 3038 2E 4443 2E 3031 2E 3032 2E 3033 1F 3230313630343136 1F 3230313630343136 1F 7C 4441544554 49 4D 45 1F 3230 313630353134313935343232 1E 30315465 6D 7065726174757265 1F 2B $32342 \mathrm{E}$ 32 1E 31344875 6D 6964697479 1F 303336 1E 303842617474657279 1F 30383303

Figure 6. Received BLE Senșor Data

Table 2. Interpretation of the Received BLF Dala

\begin{tabular}{|c|c|c|}
\hline Received Data & Length & Interpretation \\
\hline 02 & & Start of Text \\
\hline 98 & & \\
\hline 3131 & 6, & Uses Blu Network \\
\hline $\begin{array}{l}436 \mathrm{~F} 6 \mathrm{C} 6463686169 \\
30303030303030303\end{array}$ & $\mathrm{PID}(20$ & $\begin{array}{l}\text { Coldchain- } \\
0000000001\end{array}$ \\
\hline $1 \mathrm{~F}$ & US & \\
\hline $\begin{array}{l}37 \text { 34 3A } 46 \text { 30 3A } \\
3 \mathrm{~A} 38 \text { 39 3A } 41 \text { 4P }\end{array}$ & IOT_ID(12 or n) & 74:F0:7D:C9:89:AA \\
\hline $1 \mathrm{~F}$ & US & \\
\hline $\begin{array}{l}30302 \mathrm{E} 3038 \quad 2 \mathrm{E} 44 \quad 432 \mathrm{E} 3031 \\
2 \mathrm{E} 3032 \text { 2E } 3033\end{array}$ & GW_ID(12 or $n)$ & 00.08.DC.01.02.032 \\
\hline $1 \mathrm{~F}$ & US & \\
\hline 3230313630343136 & $\operatorname{FIRM}(8$ or $n)$ & 20160416 \\
\hline $1 \mathrm{~F}$ & US & \\
\hline 3230313630343136 & $\operatorname{VER}(8$ or $n)$ & 20160416 \\
\hline $1 \mathrm{~F} \bigcirc$ & US & \\
\hline$\pi 0$ & DELIMITER(1) & \\
\hline $4441544554494 \mathrm{D} 45$ & DATETIME(8) & Descriptor \\
\hline $\begin{array}{l}3230313630353134313935 \\
343232\end{array}$ & $\begin{array}{l}\text { YYYYMMDDhhmmss } \\
\text { (12) }\end{array}$ & 20160514195422 \\
\hline $1 \mathrm{E}$ & RS & \\
\hline 3031 & TYPE(2) & Temperature \\
\hline $54656 \mathrm{D} 7065726174757265$ & Descriptor & Temperature \\
\hline $1 \mathrm{~F}$ & US & \\
\hline 2B 32342 E 32 & Value & +24.2 \\
\hline
\end{tabular}




\begin{tabular}{|l|l|l|}
\hline $1 \mathrm{E}$ & RS & \\
\hline 3134 & TYPE(2) & Humidity \\
\hline $48756 \mathrm{D} 6964697479$ & Descriptor & Humidity \\
\hline $1 \mathrm{~F}$ & US & \\
\hline 303336 & Value & 036 \\
\hline $1 \mathrm{E}$ & RS & \\
\hline 3038 & TYPE(2) & Battery \\
\hline 42617474657279 & Descriptor & Battery \\
\hline $1 \mathrm{~F}$ & US & \\
\hline 303833 & Value & 083 \\
\hline 03 & ETX & End of Text \\
\hline
\end{tabular}

Meanwhile, Figure 7 is the received data from the ZigBee Sensor IOTD and Table 3 is its interpretation.

??13Coldchain-0000000001001551000006B8BDA00.08.DC.01.02.0320160416201604 16|DATETIME2016051419595401Temperature+24.914Humidity03508Battery082

0298313343 6F 6C 6463686169 6E 2D 30303030303030303031 F 30303135353130 30303030364238424441 1F 3030 2E 3038 2E 4443 2E 3031 2E 3032 2E 3033 1F 323031 3630343136 1F 3230313630343136 1F 7C 44 415445 54 49 4D 45 1F 32303136303531 34313935333532 1E 30315465 6D 706572 6 74757265 1F 2B 3234 2E 34 1E 31344875 6D 6964697479 1F 303337 1E 303842617474657279 1F 30383203

\section{Conclusion}

Figure 7. Received Zighbee Sensor

This paper designed and analyzed the communication protocol for the data communication between the IOT device and the middleware server of the IOT based Cold Chain System. Cold chain IOT deyices include sensors, and in order to collect data from these sensors, there are two existing types. One is the type which directly connects between the sen or and the middleware server of the cold chain framework, and the other type is going through a gateway in between. In order to interface various IOT modules, the connection type through a gateway is generally used. For cold chain communication modules, communication modules such as Zigbee, Bluetooth, and active RFID are used, and communication modules to the server can be designed with Ethernet, Wifi, LTE, CDMA modules. communication between the IOTD and middleware server basically utilized the client/server model, and refered to the CoAP protocol model of IETF CoRE WG. In this paper, we have designed the connection setting and data transmission between the IOTD and middleware server, and the protocol and frame structure including disconnection, with detailed specifications on them.

And, we have produced a Zigbee, bluetooth and wifi module mounted gateway and the temperature, humidity sensor in order to test the effectiveness of the proposed Cold Chain Communication Protocol, After sending the data from the IOTD to the middleware server, we analyzed the received data from the middleware server. As the result, we were able to interpretate the data sent from the IOTD as in Figure 6,7 and Table 2,3, and were able to identify that in using this cold chain data such as the temperature, humidity, and battery remains data can be collected in real time. 
Table 3. Interpretation of the Received Zigbee Data

\begin{tabular}{|c|c|c|}
\hline Received Data & Length & Interpretation \\
\hline 02 & STX(1) & Start of Text \\
\hline 98 & $\mathrm{LI}(1)$ & \\
\hline 3133 & PGI(2) & ZigBee \\
\hline $\begin{array}{l}436 \mathrm{~F} 6 \mathrm{C} 64636861696 \mathrm{E} 2 \mathrm{D} \\
30303030303030303031\end{array}$ & $\operatorname{PID}(20$ or $n)$ & Coldchain-0000000001 \\
\hline $1 \mathrm{~F}$ & US & \\
\hline $\begin{array}{l}3030313535313030303030 \\
364238424441\end{array}$ & IOT_ID(12 or n) & 001551000006B8BDA \\
\hline $1 \mathrm{~F}$ & US & \\
\hline $\begin{array}{l}3030 \text { 2E } 3038 \text { 2E } 4443 \text { 2E } 3031 \\
2 \mathrm{E} 3032 \text { 2E } 3033\end{array}$ & GW_ID(12 or $\mathrm{n})$ & 00.08.DC.01.02.03 \\
\hline $1 \mathrm{~F}$ & US & $\bullet$ \\
\hline 3230313630343136 & $\operatorname{FIRM}(8$ or $n)$ & 20160416 \\
\hline $1 \mathrm{~F}$ & US & \\
\hline 3230313630343136 & $\operatorname{VER}(8$ or $n)$ & 20160416 \\
\hline $1 \mathrm{~F}$ & US & \\
\hline $7 \mathrm{C}$ & DELIMITER(1) & \\
\hline $4441544554494 \mathrm{D} 45$ & DATETIME $(8)$ & Descriptor \\
\hline $\begin{array}{l}3230313630353134313935 \\
393534\end{array}$ & $\begin{array}{l}\text { YYYYMMDDhhmm } \\
\text { ss(12) }\end{array}$ & 20160514195954 \\
\hline $1 \mathrm{E}$ & & \\
\hline 3031 & TYPE(2) & Temperature \\
\hline $54656 \mathrm{D} 7065726174757265$ & Descriptor & Temperature \\
\hline $1 \mathrm{~F}$ & US & \\
\hline $2 \mathrm{~B} 323$ & Value & +24.9 \\
\hline $1 \mathrm{E}$ & $\mathrm{RS}$ & \\
\hline 3134 & TYPE(2) & Humidity \\
\hline $48756 \mathrm{D} 6964697479$ & Descriptor & Humidity \\
\hline $1 \mathrm{~F}$ & US & \\
\hline $303335=$ & Value & 035 \\
\hline $1 \mathrm{E} \bigcirc$ & $\mathrm{RS}$ & \\
\hline 3038 & TYPE(2) & Battery \\
\hline 42617474657279 & Descriptor & Battery \\
\hline $1 \mathrm{~F}$ & US & \\
\hline 303832 & Value & 082 \\
\hline 03 & ETX & End of Text \\
\hline
\end{tabular}




\section{Acknowledgments}

This research was supported by a grant (14TLRP-C 090585-01-000000) from Transportation \& Logistics Research Program (TLRP) funded by Ministry of Land, Infrastructure and Transport of Korean government

\section{References}

[1] D. Ko, "A Study on Design of the Cold Chain Framework Based on Cloud", Journal of KIIT, vol. 13, no. 11, (2015), pp. 79-87.

[2] L. Jiang, L. D. Xu, H. Cai, Z. Jiang, F. Bu and B. Xu, "An IoT- Oriented Data Storage Framework in Cloud Computing Platform", IEEE Transactions on Industrial Informatics, vol. 10, no. 2, (2014), pp. 1443- 1451.

[3] Z. Shelby, Sensinode and K. Hartke, "Constrained Application Protocol (CoAP)", draft-ietf-core-coap18. [2013-06--28] http://tools.ietf.org/html/draft-ietf-core-coap-18

[4] IETF 79th meeting CoRE WG, http://www.ietf.org/proceedings/79/slides/core-0.pdf
[5] H. Park, "A Study on Analysis of Internet of Things Hardware for Real Time Monitoring of Cold Chain Logistics", Journal of KIIT, vol. 14, no. 3, (2016), pp. 227-235.

[6] WHO, "Study protocol for temperature monitoring in the vaccine cold chain", the Quality, Safety and Standards (QSS), of the Department of Immunization, Vaccines and Biologicals.

[7] V. Karagiannis, "A Survey on Application Layer Protocols for the Internet of Things", Transaction on IoT and Cloud Computing, (2015), pp. 1-10

[8] D. Ko and S. Song, "Design of Smart Cold Chain Application Framework Based on Hadoop and Spark", International Journal of Software Engineering and Its Applications, http://dx.doi.org/10.14257/ijseia, vol. 9, no. 12, (2015), pp. 99-106.

[9] E. Ferro and F. Potori, "Bluetooth and Wi-Fi wireless protocols: a survey and a comparison", IEEE Wireless Communications, vol. 12, no. 1, (2005), pp. 12,26.

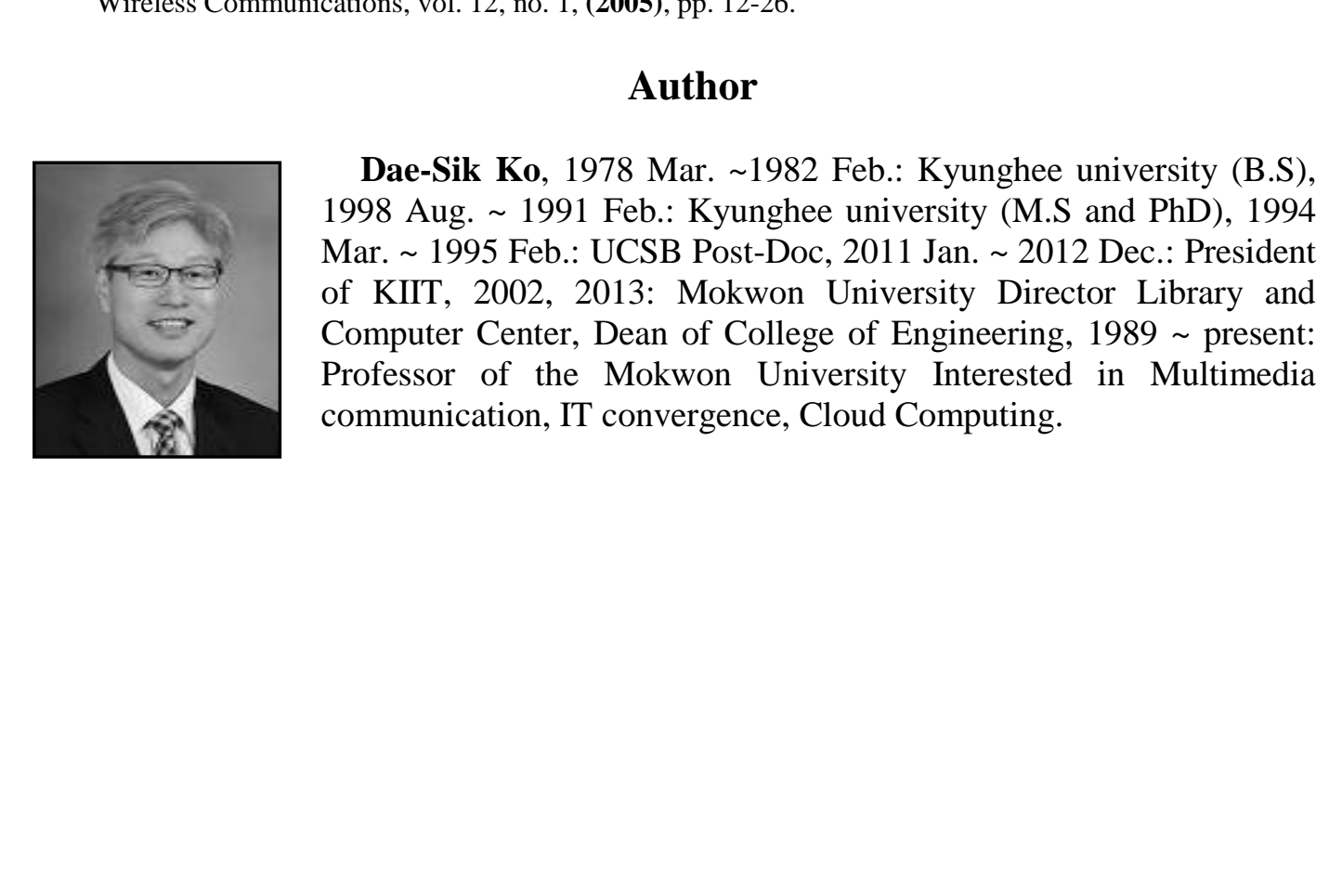


International Journal of Multimedia and Ubiquitous Engineering

Vol.11, No.9 (2016)

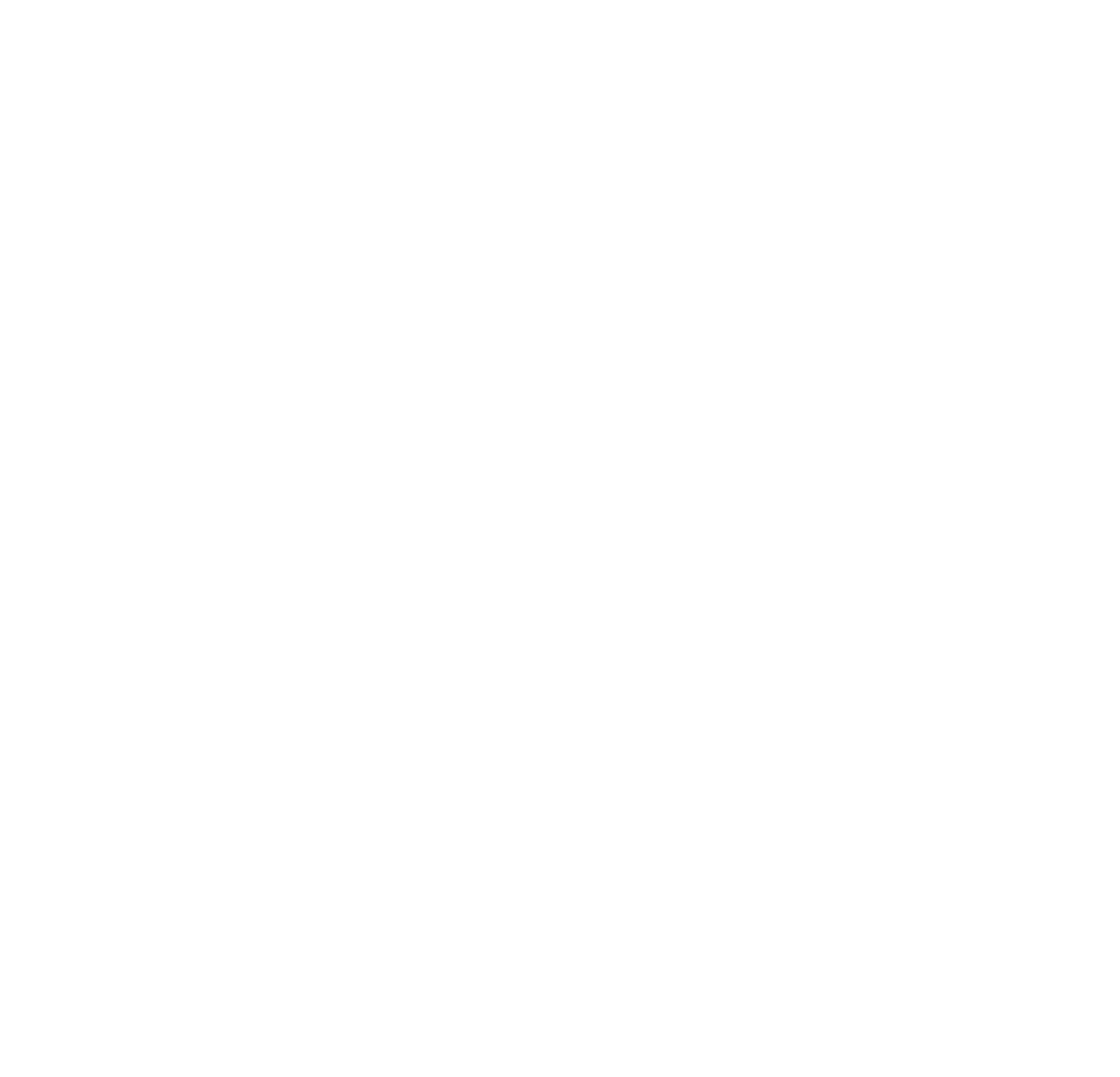

